\title{
What defines language dominance in bilinguals?
}

Article

Accepted Version

Treffers-Daller, J. (2019) What defines language dominance in bilinguals? Annual Reviews of Linguistics, 5. pp. 375-393. ISSN 011817-045554 doi: https://doi.org/10.1146/annurevlinguistics-011817-045554 Available at https://centaur.reading.ac.uk/81293/

It is advisable to refer to the publisher's version if you intend to cite from the work. See Guidance on citing.

To link to this article DOI: http://dx.doi.org/10.1146/annurev-linguistics-011817045554

Publisher: Annual Reviews

All outputs in CentAUR are protected by Intellectual Property Rights law, including copyright law. Copyright and IPR is retained by the creators or other copyright holders. Terms and conditions for use of this material are defined in the End User Agreement.

www.reading.ac.uk/centaur

\section{CentAUR}

Central Archive at the University of Reading 
Reading's research outputs online 
Annu. Rev. Linguist. 2019. 5:X-X

https://doi.org/10.1146/annurev-linguistics-011817-045554

Copyright $\odot 2019$ by Annual Reviews.

All rights reserved

Treffers-Daller

www.annualreviews.org $\bullet$ Language Dominance in Bilinguals

\title{
What Defines Language Dominance in Bilinguals?
}

\author{
Jeanine Treffers-Daller
}

Department of English Language and Applied Linguistics, University of Reading, Reading RG6 6AH, United Kingdom; email: j.c.treffers-daller@reading.ac.uk

\begin{abstract}
This article focuses on the construct of language dominance in bilinguals and the ways in which this construct has been operationalized. Language dominance is often seen as relative proficiency in two languages, but it can also be analyzed in terms of language use - that is, how frequently bilinguals use their languages and how these are divided across domains. Assessing language dominance is important because it has become clear that the level of bilinguals' proficiency in each language as well as the relative strength of each language affect performance on tasks A key distinction is made between direct_measures of language dominance, which assess an aspect of language proficiency (e.g., vocabulary or grammar), and indirect ones, which measure variability in exposure to different languages and bilinguals' use of them. The article includes an evaluation of the extent to which the latter can be interpreted as a proxy for the former.
\end{abstract}

\section{Keywords}

bilingualism, complementarity principle, input, language dominance, language proficiency, multilingualism

\section{INTRODUCTION}

Since the publication of Leopold's (1939-1949) famous longitudinal study of the bilingual development of his daughter Hildegard, it has been known that bilinguals often have a stronger and a weaker language. In the case of Hildegard, who spoke German with her father and English 
with her mother, German was the stronger language when the family lived in Germany, but English became more dominant when the family moved to the United States and German input was mainly provided by her father. Adult bilinguals are also generally dominant in one of their languages: Pavlenko (2014) discusses the case of Tzvetan Todorov, a Bulgarian-Russian bilingual from Bulgaria, who moved to Paris at the age of 23, learned French, and obtained a doctorate at the Sorbonne. He started publishing philosophical and historical works in French and eventually became French dominant.

As these two examples illustrate, bilinguals do not generally have exactly the same competencies or skills in their two languages. Romaine (1989, p. 18) notes that the "notion of balanced bilingualism is an ideal one, which is largely an artifact of a theoretical perspective which takes the monolingual as its point of reference." Baker (2006) concurs and points out that bilinguals are rarely equally competent in all four skills (reading, writing, listening, and speaking) and across all domains and situations. Unfortunately, the myth of the balanced bilingual persists not only among the wider public but also in academic circles (Grosjean 1989, 1998; Treffers-Daller 2016).

There is also a considerable amount of terminological confusion around the notion of language dominance because widely different definitions and operationalizations of this construct are being used, and there is no consensus on how to measure it (Unsworth 2016). Researchers are not always aware of the range of perspectives on language dominance and the many approaches to measure it, and they opt for operationalizations that are convenient without providing principled reasons for their choices. A key aim of this article is to raise awareness of the issues and choices that need to be made in defining and measuring the construct. To begin, a few words must be said about what it means to be bilingual. A widely used definition is that of Grosjean (1998, p. 132), which posits that bilinguals are people who use two (or more) languages (or dialects) in their everyday lives. The difficulty with the term bilingual is that it covers individuals with widely different abilities in their languages; the term is being used to refer to individuals who can say only a few meaningful sentences in another language as well as to those who have extensive oral and written abilities in two or more languages. A further distinction is often made on the basis of the time at which an individual becomes bilingual (age of onset): Early bilinguals acquire their two languages before the age of 6, and late bilinguals start using a second language after the age of 12 (Altarriba \& Heredia 2011). Baker (2006) provides a fuller 
discussion of the many dimensions along which bilinguals differ from one another, but Luk \& Bialystok (2013) show that the two key underlying dimensions of the bilingual experience are language proficiency and language use. Given the importance of these two dimensions for understanding variability among bilinguals, I use them in this article to structure my discussion of the construct and the measurement of language dominance. Because most academic literature focuses on children, this article necessarily reflects this emphasis, but information about language dominance in adult bilinguals is provided whenever possible.

First, I review different views of language dominance and proposals to measure this construct (Section 2). Then, I look at the two key dimensions of language dominance: language proficiency (Section 3) and language use (Section 4). In each section, the focus is first on the meaning of the notions and then on the ways in which these can be operationalized and measured. I make a key distinction between direct measures of language dominance, which assess an aspect of language proficiency (e.g., vocabulary or grammar), and indirect ones, which measure variability in exposure to different languages and in bilinguals' use of these, because it is generally assumed that it is differences in exposure and use that lead to language dominance in the first place. The final section offers a summary and outlook toward the future.

\section{THE CONCEPT OF LANGUAGE DOMINANCE AND ITS OPERATIONALIZATION}

As pointed out by Fishman (1972), it is important to distinguish between societal language dominance and language dominance in the individual. In a given society, one language can be dominant in that it is the one most frequently used in education, government, and other functions, as is the case with Dutch in Flanders, the northern part of Belgium. Although Dutch is the language that many Flemish inhabitants of Flanders know best and use for most domains, this is not necessarily the case for people from other regions in Belgium, such as those from Wallonia or Brussels, or for immigrants from other countries who live in Flanders. Residents from other regions or other countries generally speak one or more languages at home - for example, French, German, or immigrant languages — in addition to Dutch (De Houwer 2003). They are likely to differ from the Flemings in that they are not necessarily Dutch dominant, although a considerable proportion of bilingual or trilingual families in Flanders report that only Dutch is spoken at home, particularly by children (De Houwer 2007). 
These examples illustrate that societal language dominance is linked to, but not identical with, individual language dominance; that exposure to and use of languages are key to the development of language dominance; and that dominance can change over time (Argyri \& Sorace 2007, Hohenstein et al. 2006). Thus, language dominance is a complex phenomenon with linguistic, sociolinguistic, and psycholinguistic dimensions (Lanza 2004). Yip \& Matthews (2006) agree but consider language dominance to be first of all a property of the mind, although they recognize that it is influenced by sociolinguistic parameters, such as quantity of input, and that it reveals itself in directly observable phenomena, such as fluency markers. Because there are so many aspects to language dominance, Montrul (2016, p. 16) provides a wider definition of the construct and argues that language dominance includes "a linguistic proficiency component, an external component (input), and a functional component (context and use)."

Studying a phenomenon of this complexity is challenging. Given that for many years $\underline{\text { Cook }}$ $\underline{(1991}, \underline{2016})$ and Grosjean $(1985, \underline{1998)})$ have emphasized the need for researchers to take into account both languages of a bilingual (and not just the weaker language), linguists as well as psychologists are increasingly aware that bilinguals' abilities in both languages need to be measured (Hulstijn 2012). It is, however, not just the level of knowledge or use a person makes of both languages but also the relative strength of each that affects performance on tasks. Argyri

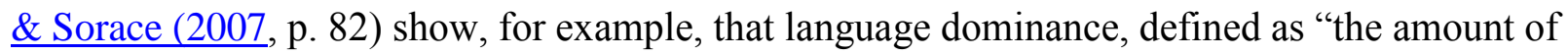
input the bilinguals receive in each language," modulates crosslinguistic influence in GreekEnglish bilingual children: The English-dominant bilinguals use overt Greek subject pronouns in contexts where null subjects are required, but this is not the case in Greek-dominant children. In a similar vein, in a study among Chinese-English bilinguals, Wang (2013, p. 739) demonstrates that language dominance, defined as "a global measure of relative frequency of use and proficiency in each language," offers a better explanation of translation priming effects than does language proficiency on its own. Most recently, Kootstra \& Doedens (2016, p. 711) show that language dominance, which they define as "a measure of bilinguals' personal experience with both languages," is also an important factor in cross-language structural priming tasks, in that priming effects are often visible only in one direction, namely from the dominant to the nondominant language.

One of the founding fathers of the field of bilingualism, Uriel Weinreich (1953, p.80), points to a wide range of factors that need to be considered in "dominance configurations." In addition 
to relative proficiency, Weinreich lists emotional involvement of the speaker with both languages and the order in which the languages are learned, as well as variables that appear to belong to societal language dominance, such as a language's "function in social advance" (p. 80). The latter concept refers to the perceived value of a language for a person's career prospects, whether or not a language is used in oral or visual mode, and the "literary-cultural value" (p. 80) of the languages. Although some of these variables (e.g., the order in which languages are learned) are probably better seen as factors that explain the development of language dominance but are not a constituent part of the construct itself, it is interesting to note that early observers included a much wider range of variables in the discussion than is currently the case.

As mentioned above, there are two key dimensions of language dominance, namely language proficiency (how well languages are known either productively or receptively) and language use (how frequently bilinguals use their languages and how these are divided across domains such as home, work, and school) (Fishman et al. 1968, Grosjean 2010, Treffers-Daller 2016). According to Luk \& Bialystok (2013), these two dimensions are the basic underlying elements of the bilingual experience itself and need to be included in any description of this phenomenon. Fishman et al. (1968, p. 484) give a very helpful interpretation of both terms, defining language proficiency as "what a person can do" and language use as "what a person typically does." For the purposes of this review, the psycholinguistic dimension of fluency-which refers to the automaticity of, for example, lexical retrieval, speech rate, and frequency of pauses (Segalowitz 2010) - is subsumed under the dimension of language use. There are, however, also clear links between proficiency and fluency in Segalowitz's model of second-language fluency, because one of the dimensions of fluency, cognitive fluency, refers to the underlying processes that make language production possible.

Not all researchers agree that the term proficiency is appropriate for use with bilinguals (De Houwer 1998), but despite this critique, the term is widely used in research into first- and second-language acquisition as well as bilingualism. If we use the term language proficiency, it is important to realize that this is a fairly narrow construct, which mainly covers what Bachman $\underline{\text { \& Palmer (2010) }}$ call grammatical knowledge - that is, knowledge of syntax, morphology, phonology, phonetics, and vocabulary. To Bachman \& Palmer (2010), grammatical knowledge is only one component of the overarching construct known as language ability, which refers to the ability to use language communicatively and is thus quite different from language proficiency. 
Language ability consists of language knowledge and strategic knowledge, where the latter refers to a set of metacognitive strategies, including goal setting and planning. Language knowledge is also much wider than grammar and vocabulary knowledge because it also covers textual, functional, and sociolinguistic knowledge. As the remainder of this article shows, so far language dominance has been mainly considered in terms of grammatical knowledge and hardly ever in terms of any of the other components of language ability, which is quite remarkable. Because of its popularity among researchers, the term language proficiency is used here, but language ability is briefly mentioned in the final section, which addresses avenues for future research.

Because language dominance is a multidimensional construct, it can be operationalized in different ways. Anyone wishing to measure language dominance, therefore, needs to deal with several issues in relation to its operationalization and measurement. The first of these is the choice of the measure. Although researchers have used a wide range of different measures, they do not always offer reflections on why they have chosen to operationalize the construct in a particular way. The choice of the measure should of course be guided by the purposes of the investigation, because there is no single "best" measure (Bedore et al. 2012, p. 623) that is suitable for all groups and all purposes. Second, there is the issue of the comparability of measures across languages. Because of typological differences among languages, measures such as the mean length of utterance (MLU; Brown 1973) are not easily comparable across languages, and the same is true for other measures, including standardized tests. Third, measures of language dominance need to be validated in some form. Flege et al. (2002) suggest that validation needs to be done by investigating to what extent measures of language dominance can predict behavior on other variables. Fourth, the actual computation of indices of language dominance can be carried out in a variety of ways, for example by computing the difference between measures for language $\mathrm{A}$ and for language $\mathrm{B}$ or by computing a ratio of measures in both languages; each method has its advantages and disadvantages (Birdsong 2016, TreffersDaller 2016). Fifth, and finally, researchers interested in determining whether or not the bilinguals in their study are balanced will need to choose a cutoff point that separates the participants in dominant and balanced bilinguals. In many cases, researchers do not make clear what the cutoff point is and why it was chosen, although these choices clearly have a direct impact on the number of balanced and dominant bilinguals that are found in the study and thus on subsequent analyses of differences between those groups (for relevant discussion, see 
Treffers-Daller 2016).

\section{LANGUAGE DOMINANCE AND LANGUAGE PROFICIENCY}

Language dominance is most often interpreted as referring to the relative strength of a bilingual's proficiency in each language, with the dominant language being the "more proficient" or "further developed one" (Snape \& Kupisch 2016, p. 190). Because language proficiency is a multidimensional construct comprising syntax, semantics, morphology, phonology, phonetics, and vocabulary, there remains the question of which of these components should be prominent in the measurement of language dominance. The choice of the component is important because the classification of children into dominance groups differs depending on the measure chosen. In their study among 1,029 four- and five-year-old Spanish-English bilinguals, Bedore et al. (2012) show, for example, that more children were classified as balanced when semantic criteria were used than when morphosyntactic criteria were employed. In many studies, for practical rather than principled reasons, researchers choose self-ratings to obtain information about language dominance, but the validity of these is questionable (Treffers-Daller 2016). Self-ratings of the four skills (reading, writing, speaking, and listening) are also problematic, because the constructs covered by the four skills are not easily separable (Hinkel 2006) and the skills are too broadly defined (see Bachman \& Palmer 2010 for relevant discussion). Those who instead opt for direct measures that assess an aspect of language ability often choose vocabulary tests, because vocabulary appears to be more easily quantifiable than other components of language proficiency (Milton 2009) and because of the availability of parallel vocabulary tests for some languages. In this section, I first look at language dominance in grammar, in particular in children, and then at other components of language proficiency.

\subsection{Language Dominance in Morphosyntax}

A key interest of researchers working on the syntactic development of bilingual children is whether the grammar of the nondominant or weaker language develops along the same path or at the same rate as the dominant or stronger language. In a seminal article based on longitudinal

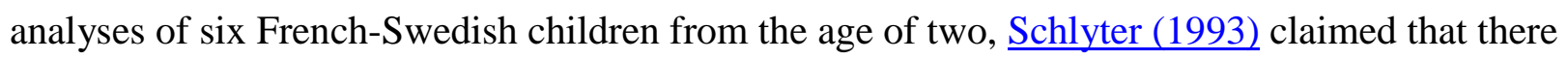
is a fundamental difference between the stronger and the weaker language, because in the stronger language finiteness, word order, and placement of negation are fully developed, whereas 
in the weaker language there is considerable variation with respect to the acquisition of these aspects of grammar. In some cases, Schlyter claimed, these elements are not acquired at all and others are observed less frequently, which makes the development of the weaker language similar to that of a second language. This article, which is often seen as the starting point of the weak language hypothesis, inspired many researchers to investigate further the syntactic development in the weaker language in bilinguals. In a study of three children who were growing up in Sweden with Italian, French, or Swedish as the weaker language, Bernardini \& Schlyter $\underline{(2004)}$ provided some evidence for the existence of asymmetrical developments in bilingual children's grammars in the stronger and weaker languages. In these children, the higher categories - DP, PP/VP, IP, and CP — were all in place before the age of 3;5, as in monolingual children, but in the weaker language these were severely delayed. Importantly, the study authors also showed that the stronger language supported the development of grammar in the weaker language, in ways similar to those discussed by Gawlitzek-Maiwald \& Tracy (1996).

Thus, although many authors agree that there can be delays in the development of aspects of syntax in the weaker language of dominant bilinguals, Meisel (2007) argues that there is no evidence of incomplete acquisition in the available literature, because the children eventually catch up, and many of the developments differ quantitatively rather than qualitatively from those found in monolingual children. According to Meisel (2007, p. 506), the differences are not to be attributed to failure of acquisition, but to "covert code-switching, by which structural properties of the other language are activated but no lexical material from that language is inserted." Most other researchers would refer to this phenomenon as interference, transfer, or crosslinguistic influence (Grosjean 2012, Jarvis \& Pavlenko 2008, Treffers-Daller 2009). These phenomena occur because the less activated language is never completely inhibited: Even in a monolingual mode, when bilinguals are speaking with or listening to monolinguals of one language they know, features from the other language may still appear in their output (Grosjean 2012). Such phenomena are not to be interpreted as evidence for incomplete acquisition but rather as the byproduct of the coactivation of two systems in the mind of the speaker.

In her analysis of German-English bilingual children, Döpke (2000) notes that there is no evidence that the weaker language is being acquired as a second language. Because the surface structures of German and English appear to be very similar, it may take bilingual children some time to acquire the target structures in each language, but the path of development is similar to 
that of monolingual children and not to that of adult second-language learners. Further discussion about the differences in syntactic development of bilingual children and monolingual children (or weaker and stronger languages) tends to focus on particular vulnerable domains (Meisel 2001). Such vulnerable domains are often claimed to be those where the grammar interacts with other cognitive systems, such as pragmatics, as proposed by $\underline{\text { Sorace \& Serratrice (2009) } \text { and Sorace }}$ $\underline{(2011)}$ in the interface hypothesis.

As for the measurement of language dominance in bilingual children, Genesee et al. (1995) noted the absence of standardized measures of language dominance and called for greater clarity in the measurement of the construct to avoid idiosyncrasy and make studies more comparable. They used the MLU, upper bound (the longest utterance produced by the child during one session), word types, and the percentages of multimorphemic utterances (MMU) to measure language dominance among five French-English bilingual children. They concluded on the basis of these criteria that three of the five children were English dominant, one was French dominant, and one was balanced. With the help of discriminant function analysis, they investigated whether the different criteria were useful to determine language dominance and claimed that word types and MMU were valid indices of language dominance. Genesee et al. (1995) did not compute indices of language dominance (e.g., by subtracting scores in one language from another language), nor did they offer a discussion of the ways in which the cutoff point between dominant and balanced categories was chosen. Therefore, we do not know how exactly the classification was made. However, it is highly commendable that they tried out different criteria, obtained converging evidence from different measurements, and investigated whether their operationalization of language dominance could be used to predict code-switching behavior. They also briefly pointed to difficulties in comparing measures across languages: Because of differences in inflectional and derivational morphology, and differences in the use of function words such as articles, auxiliaries, and pronouns, MLU scores are hardly comparable across languages (De Houwer 1990). Not all researchers are aware, however, that other measures of language dominance - such as the numbers of types and tokens, upper bounds, and the number of MMU - are not easily comparable between languages either. As explained in Treffers-Daller et al. (2018), types can be defined in different ways, and the number of types one finds depends on the definition that has been chosen. If a type is considered to be equivalent to a lemma, all inflected forms (works, working, worked, etc.) are counted as tokens of one type (e.g., work), but 
derived forms (worker, unworkable, etc.) are seen as different types. By contrast, if a type is defined as a word family, inflected as well as derived forms are seen as tokens of the same type, which means the total type count is lower when the unit of counting is the word family than when it is the lemma. In addition, counts of types in different languages may differ dramatically if one language is highly inflected (e.g., Polish) and the other one is not, which leads to inflated scores for the highly inflected language. A solution is to apply lemmatization before counting types, which corrects to some extent for typological differences (Treffers-Daller \& Korybski 2016). There are also important differences between languages in their use of function words (articles, pronouns, copulas, modal and auxiliary verbs, etc.), which affect counts of types and tokens. The longest utterance in agglutinative languages such as Turkish may therefore be much shorter than the longest utterance in German or English, because in Turkish many grammatical features are expressed in bound morphemes rather than free morphemes. The number of multimorphemic utterances, by contrast, is likely to be much higher in agglutinating or highly inflected languages. However, as Daller et al. (2011) show, it is possible to adjust calculations of language dominance indices to correct for such typological differences.

In studies of the first two to three years of the development of bilingual children, MLU is one of the most widely used measures of language development. It is therefore not surprising that MLU is also frequently employed to operationalize dominance, despite the difficulties involved in comparing it across languages (Deuchar \& Muntz 2003, Kupisch 2008, Schmeißer et al. 2016, Yip \& Matthews 2006). Yip \& Matthews (2006) argue that for agglutinating languages such as Turkish, MLU should be computed in morphemes, but for isolating languages such as Cantonese it should be computed in words. In a language pair such as English-Cantonese, they argue that an index of language dominance should be measured in words (MLUw) rather than morphemes because in the early stages inflections are not yet available. They coin the term MLU differential for this index and define it as "the difference between MLU scores for a child's two languages at a given sampling point or (expressed as a mean) over a period of development" (Yip \& Matthews 2006, p. 108). Kupisch (2008) also counts MLU in words rather than morphemes in German-French bilingual children and adds a word of caution to comparisons of MLU between languages because MLU scores start rising as soon as articles appear in a child's language.

For older children and adults, the use of MLU no longer offers an appropriate indication of grammatical knowledge. According to Scarborough et al. (1991), MLU correlates well with 
other measures of grammatical development up until an MLU of 3 but not when MLU exceeds this level. With older children, it is not necessary to rely solely on transcripts of spontaneous speech on which MLU or other indices are computed, because it becomes possible to use grammar tests. Verhoeven (2007), for example, created a Turkish and Dutch sentence repetition test as part of a test battery that measured a wide range of abilities among Turkish-Dutch fiveyear-old children in the Netherlands. The sentence repetition test for each language contains 40 critical morphosyntactic features, carefully chosen on the basis of available descriptive grammars. An effort was made to ensure the sentences were of equal length in both languages, and the number of nominal and verbal phrases was kept constant across languages, too. Verhoeven did not compute dominance indices, but the results show that Turkish was the children's stronger language. Measurements were taken at the beginning and at the end of kindergarten, and the discrepancy between the two languages became smaller over time. Whereas the sentence repetition task, therefore, turned out to be a very useful instrument to measure language dominance in this group, an issue that deserves further thought is how one can ascertain comparability of grammar domains across languages and establish whether the tests are equally difficult in each language. Sentence repetition tasks were also developed for a wide range of languages as part of the Bilingualism-SLI COST Action IS0804 (Chiat et al. 2013, Marinis \& Armon-Lotem 2015).

Although the aim of the COST Action was to develop diagnostic tools for disentangling bilingualism and specific language impairment (SLI) in six- to eight-year-old children, the sentence repetition task offers very interesting opportunities for measurements of language dominance, too. As explained by Marinis \& Armon-Lotem (2015), the sentence repetition tasks were very carefully designed to ensure that the grammar domains included in the 56 sentences were comparable across languages. Sentence repetition tasks were also developed by GutiérrezClellen et al. (2006) as a diagnostic tool to disentangle bilingualism and SLI in Spanish-English children. As part of this project, they also highlighted the importance of language dominance and showed that Spanish-dominant bilinguals do not differ significantly from monolingual children on the sentence repetition task and are not more likely to be misdiagnosed as having SLI than monolingual children.

An alternative to sentence repetition tasks is to use tests of (receptive) grammatical ability, but these exist for only a few languages. For English, two such tests are the Clinical Evaluation 
of Language Fundamentals (CELF), which was developed by Wiig et al. (2013), and the Test for Reception of Grammar (TROG), developed by Bishop (2003). Such tests could be used for the measurement of language dominance if parallel tests could be developed in different languages. The problem is, of course, that this is a very difficult task, because of the typological differences among languages.

\subsection{Language Dominance in Vocabulary Knowledge}

Many researchers choose vocabulary as the domain to measure dominance, probably for practical reasons because of the availability of receptive vocabulary tasks in different languages. Although such tests have probably more validity than questionnaires or self-assessments, it is important to realize that tests that measure receptive vocabulary knowledge - that is, the ability to recognize the meaning of a word if presented with this word in oral or written form - assess only a subcomponent of word knowledge. It is not possible to describe all aspects of word knowledge in detail here, but the most widely used overview of what it means to know a word is provided by Nation (2013), who distinguishes between receptive and productive knowledge about form, meaning, and use. Knowing the meaning of a word in another language can be quite complicated because often there is no one-to-one translation equivalent of a word due to linguistic relativity. As shown in Pavlenko (2009), translation equivalents are not always conceptual equivalents. For example, bank in Dutch is used for two types of seating for which English uses different words: sofa 'a long soft seat with a back and usually arms, large enough for two or more people to sit on,' and bench 'a long seat for two or more people, often of wood and usually used outside' (http://dictionary.cambridge.org/us/dictionary/). Although English bench and Dutch bank are cognates, their meanings overlap only partially. Dutch bank has an additional, nonrelated meaning, namely 'institution that keeps and lends money’ (English bank), which is not shared by bench; in turn, however, bench has other additional meanings related to the core meaning of a long seat, namely 'the judge or magistrate in a law court, or the place where he or she sits,' which is not shared by the stand-alone form bank in Dutch. Frequent words, in particular, often have multiple meanings (Zipf 1945), and it is generally the context in which they are used that helps to identify the intended meaning (Firth et al. 1957). These different meanings are highly relevant for psycholinguistic experiments because the existence of additional meanings affects speed of lexical retrieval, in that words that have a number of 
different but related meanings are accessed faster than ambiguous words with different unrelated meanings ( ways in compounds and fixed expressions that are unique to each language. Examples of Dutch compounds with bank are toonbank 'shop counter' and draaibank 'turning lathe,' and an example of a fixed expression with bank is door de bank genomen 'generally.' For bench, examples are benchpress and benchmark or frontbenchers (government ministers or spokespersons from the shadow cabinet who sit on the front benches in the UK Parliament) and backbenchers (members of parliament who do not serve as ministers or are not members of the shadow cabinet).

Knowledge about expressions of different types, often called formulaic sequences (Wray 2000), is an integral part of word knowledge, but one that is very challenging for nonnative speakers. Finally, word associations overlap only partially for translation equivalents, too. The most common word associations with Dutch bank are geld 'money,' zitten 'sit,',' according the thesaurus of the University of Leuven (), whereas sit, seat, and park are the most common associations with bench according to association norms from a database of the University of South Florida (http://robseward.com/blog/2009/02/23/word-association-apps/). Unsurprisingly, money is not associated with bench at all. The examples of bank and bench illustrate that socalled translation equivalents are often not really equivalent in two languages (see House 1997 for further discussion). In addition, some words do not have a translation equivalent at all in another language. This means that it is not possible to claim that bilinguals have similar lexical knowledge in two languages even if they obtain similar scores for each language on vocabulary tests that are purportedly equivalent.

Because vocabulary knowledge is a highly complex construct, there is no single test that can tap into all the different aspects of it. Most vocabulary tests that are being used to measure language dominance examine words in isolation, thus avoiding the complexities of different word meanings being associated with different contexts of use. The Peabody Picture Vocabulary Test (PPVT) (Dunn \& Dunn 2007), for example, is a widely used measure of receptive vocabulary that can be employed to assess language dominance. For this test, respondents need to point to one picture out of a choice of four that corresponds to the meaning of a word previously presented in oral form. For the purposes of the measurement of language dominance, the advantage of this test is that parallel forms exist for other languages, although some concerns 
exist about possible cultural biases in the use of the PPVT (Haitana et al. 2010). For British English there is the British Picture Vocabulary Scale (Dunn et al. 1997), for French the Échelle de vocabulaire en images Peabody (Dunn et al. 1993), for Spanish the Test de Vocabulario en Imagenes Peabody (Dunn et al. 1986), and for Welsh the Prawf Geirfa Cymraeg (Gathercole \& Thomas 2007). For younger children who cannot take tests, a solution is to use the MacArthur Communicative Development Inventories (CDI) (Fenson et al. 1993), which are parental report forms for infants (8- to 18-month-olds) or toddlers (16- to 30-month-olds) that parents can fill in to indicate which words their children know receptively and/or productively. This tool now exists for more than 60 languages (Dale \& Penfold 2011), and there is also a bilingual version for

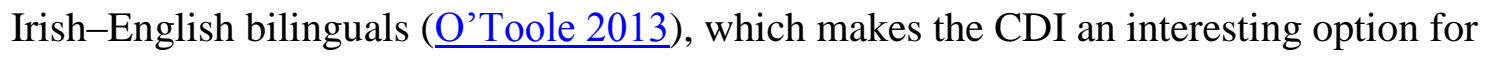
measuring language dominance.

Adapting an existing test to a new language is difficult because it is not possible to simply translate the items that are relevant in one language into another language, not only because of intercultural differences but also because of a range of other factors, such as word frequency, word length, imageability, concreteness, age of acquisition, and neighborhood density (Bird et al. 2001), which may differ across languages. The neighborhood density of words is the number of words that differ from a target word by the addition, substitution, or deletion of one phoneme in any word position. In English, the neighbors of rat include the words brat, rot, and at (Luce \& Pisoni 1998), but the neighborhood density of the translation equivalent of rat in other languages will be different. Therefore, Gathercole et al. (2013) conclude that translating tests between languages is similar to giving a piano player a musical test that was created for the drums. Instead, test items for a new test in a different language need to be carefully sampled on the basis of the criteria mentioned above, and they are likely to overlap only partially for parallel tests in different languages.

An alternative to adapting an existing vocabulary test is to create one on the basis of a set of pictures. This is the approach taken by Haman et al. (2015), who developed Crosslinguistic Lexical Tasks (CLTs) for five-year-old children as part of the Bilingualism-SLI Cost Action IS0804. Such tasks are particularly important for researchers and practitioners interested in establishing whether or not children who present with vocabulary difficulties are delayed in their language development. Haman et al. (2015) created a database of more than 1,000 pictures of actions and objects that groups of adult speakers of 34 different languages were asked to name. 
They selected a set of 30 nouns and 30 verbs associated with the pictures as the candidate words for the CLTs in different languages. They took care to ensure that the words were comparable with respect to complexity and avoided cultural bias by including variants of pictures in the database (e.g., a woman with or without a headscarf). Because the CLTs were carefully created for different languages, the results are likely to be comparable across languages. It is therefore no doubt possible to use the CLTs to measure language dominance in bilingual children. Collecting reaction times for this task is possible, too, which creates an interesting option for the measurement of dominance in lexical retrieval.

Because there are so many aspects to vocabulary knowledge, it can be a good idea to include a variety of measurements in a study to assess different components of vocabulary knowledge, but authors who have done this have often found that language dominance is task dependent. Bahrick et al. (1994) studied language dominance among 801 Mexican-American immigrants who had lived in the United States for up to 50 years and who had come to the United States between the ages of 10 and 26 . The authors found that most immigrants became dominant in English in a category fluency task after twelve years of residence in the US, but very few became dominant in vocabulary recognition. Informants who were younger than 13 at immigration and had had little schooling in Spanish were most likely to become English dominant. Even though this study was cross-sectional rather than longitudinal, it provides considerable evidence that language dominance can change over time not only in young children but also in adult bilinguals (but see Kupisch \& van de Weijer 2016 for a different view). Researchers who have compared the vocabulary knowledge of bilinguals in two languages have sometimes found that bilinguals have smaller vocabularies in each of their languages than their monolingual age-mates do. This was the case, for example, in the study that Bialystok et al. (2010) carried out among 1,738 children (996 bilinguals and 772 monolinguals) between the ages of 3 and 10 for whom English was either the first or the second language. The authors found that bilingual children had smaller receptive vocabularies in English than did monolingual children in all age groups, as measured with the PPVT (Dunn \& Dunn 2007). The authors found a nine-point difference between the results of the monolinguals and the bilinguals in their sample. However, as pointed out by De Houwer et al. (2014), it is likely that English was the weaker language for many of the bilingual children in the study. As indicated by De Houwer et al. (2014) and Pearson et al. (1993), when bilingual children are divided into dominance groups and are compared with monolinguals only 
in their stronger language, such discrepancies between monolinguals and bilinguals are not found (see Antoniou 2019 for further discussion of the pitfalls of comparing the competences of bilinguals and monolinguals). That exposure patterns need to be taken into account in the measurement of bilingual abilities is also a key finding of Gathercole \& Thomas (2009) and Gathercole et al. (2013). Therefore, I now turn to how language use can be analyzed for the purpose of the measurement of language dominance.

\section{LANGUAGE DOMINANCE AND LANGUAGE USE}

In addition to direct measures of language dominance that tap into aspects of language proficiency, it is possible to measure dominance indirectly - that is, through experience-based variables such as exposure to both languages in the input to bilingual children as well as children's own output (Bedore et al. 2012, La Morgia 2016, Unsworth 2016). Measuring dominance in this way has become more popular with the rise of usage-based approaches to language acquisition and development, which highlight the importance of language use rather than innate mechanisms such as Universal Grammar. The assumption behind indirect measures is that dominance relationships are at least to some extent a function of the amount of input children receive in both languages. Assessing dominance through exposure measures is potentially easier than using direct measures, because it eliminates the necessity to find or develop vocabulary or grammar tests in two languages that cover a relevant sample of words or grammar items of each language and are comparable in difficulty. It is also a solution in bilingual and multilingual contexts where standardized tests are not available for the varieties under study.

However, characterizing the input patterns in bilingual children is very challenging, too, because there are so many parameters on which the bilingual experience varies. A major factor is age of onset of bilingualism: Early or simultaneous bilinguals hear two languages from birth or from early childhood, whereas late or sequential bilinguals start hearing one of their languages after age 12 (Altarriba \& Heredia 2011). This means that cumulative exposure to each language differs considerably over time depending on the age of onset of each language. Another variable is the distribution of languages across domains and interlocutors: Some children hear only the minority language at home and the majority language in other contexts, whereas others hear both 
languages at home and the majority language elsewhere. The quality of the input may also differ across contexts and interlocutors: An important issue is whether or not children receive input or are exposed to input from different sources (for relevant discussion, see Jia \& Fuse 2007, Place \& Hoff 2011). Some bilinguals may receive additional support through community groups or complementary schools, whereas others do not have access to such resources. Furthermore, there are differences in the amount and type of code-switching that is practiced in different settings, in that in some contexts languages are kept strictly separate whereas others are more tolerant of code-switching. In addition, the social factors mentioned above interact with typological differences between languages: Some bilinguals speak closely related languages such as Spanish and Catalan, whereas others speak typologically distinct languages such as French and Turkish. Whether or not a bilingual has literacy skills in both languages, as well as whether or not the writing systems are similar or different, also plays a role (Bialystok et al. 2005). All these variables have an impact on the language profiles of bilinguals and on the dominance relationship between their two languages. Because of the wide range of parameters involved in the bilingual experience, each bilingual seems to have a unique profile. This is particularly the case for children who grow up with more than two languages. In the course of a bilingual's life, dominance patterns may vary as the social circumstances in which bilinguals live change. The wider social context also interacts with variables often used to measure language dominance. According to Lim et al. (2008), for immigrant populations in Europe or North America, age of arrival and length of residence are important variables that can be used to assess language dominance, but these variables are much less useful for multilingual populations in contexts where English is learned before the age of six.

Bedore et al. (2012) looked into the relationship between direct and indirect measures of language proficiency and how these could be used to measure language dominance in their study of over 1,000 four- and five-year-old Spanish-English bilingual children. They measured language dominance by computing difference scores for semantic and morphosyntactic measures and divided the subjects into five language dominance categories groups according to these measures. They also obtained detailed information about the children's exposure to both languages and their use of each through parental questionnaires. Because input and output measures were found to correlate strongly $(r=0.95)$ with one another, they created a composite variable based on both measurements to represent children's current exposure to and use of both 
languages. A key finding of the study was that age of first exposure to English explained less variance in language dominance $(35 \%)$ than the composite variable that measured current patterns of use $(60 \%)$. The input and output measures agreed in classifying most children in one of the five language dominance categories. Only $15 \%$ of the children were classified differently depending on whether an input or an output criterion was used. Differences in the children's performance on the semantic and the morphosyntactic tasks make it clear that whether or not a child is classified as dominant in one or the other language depends crucially on the choice of the outcome variable. The authors also suggest that input is particularly crucial for vocabulary development and that output is key to syntactic development, but this claim is not developed further in their article.

In a study of 18 Dutch-English bilingual children of high socioeconomic status (SES) in the Netherlands, Unsworth (2016) further explored the relationship between direct measures of language dominance and measures of exposure. The aim of the study was to establish to what extent indirect measures could be used as a proxy for language dominance, defined in the study as relative proficiency. The results show that there are indeed significant correlations between some measures of exposure and use of English on the one hand (e.g., amount of input at home and at daycare/school) and direct measures of language dominance (e.g., MLU differentials) on the other hand. The researchers also found that children who were dominant in Dutch on the linguistic measures (i.e., those showing a difference of more than 1 SD between the measures for each language, for example on MLU) were exposed to Dutch at least $65 \%$ of the time. Children whose scores on linguistic measures were more balanced had less exposure to Dutch. Perhaps the most interesting finding in the study is that children's own use of the two languages was clearly related to the direct measures of dominance: Those who were classified as dominant in Dutch on the MLU differentials reportedly used Dutch $90 \%$ of the time. This illustrates the point that it is not only the proportion of exposure to a language but also the proportion of bilinguals' use of each language that provide key information about their dominance. The author concludes that for this particular group of children, it is indeed possible to use indirect measures as a proxy for direct measures of language dominance, even though further research is needed to establish to what extent this is also true for other groups, such as children of lower SES.

The relationship between quantity of input and grammatical development has received a great deal of attention among researchers working on bilingual first-language acquisition. In this 
field, language dominance is often found to be a key variable that modulates outcomes of bilingual development (but see De Houwer 1998; De Houwer \& Bornstein (2016) for a different view). Interestingly, no differences in development between monolinguals and bilinguals are found in studies that focus on the dominant language of a bilingual - that is, the language in which the child receives more input—or in studies involving children who receive input that is roughly balanced between the two languages (Meisel 2007). As Blom (2010) points out, there are far fewer studies of the development of the nondominant language in early bilinguals. The existing studies reveal that there are indeed important differences between bilinguals and monolinguals if one focuses on the language in which a child receives less input. An example is La Morgia's (2016) study of interactions between four Italian-English bilingual children and their mothers. Among the children in this study, only one received input in Italian (the nondominant language) $35 \%$ of the time, whereas the others received Italian input between $15 \%$ and $25 \%$ of the time. La Morgia found qualitative and quantitative differences in grammatical development among those receiving 20\% Italian input or less and concluded that 20\% input is not enough to develop the heritage language as a strong language. However, according to Meisel (2007), the observed differences in the nondominant language of bilingual children are indicative of delays, but reduced input is unlikely to lead to acquisition failure of morphosyntax.

Establishing the minimum quantity of input for acquiring the morphosyntax or the vocabulary of a language is not possible at present, also because it is not only the quantity but also the quality of the input that matters, and capturing the quality of the input is even more difficult than measuring its quantity (see Blom 2010 and Thordardottir 2011 for relevant discussion).

In order to argue that indirect measures can serve as a proxy for measuring dominance in bilinguals, it is of course essential to demonstrate that such measures correlate with each other. Several observers do indeed report such correlations (e.g., Jia, Aaronson \& Wu 2002, Lim et al. 2008, Unsworth 2016). Unsworth (2016) found substantial correlations between these two types of measurements, with correlation coefficients ranging from 0.5 to 0.9. In other studies, Lim et al. (2008) found more moderate correlations (around $0.4-0.5$ or even lower). If correlations are moderate to low, the amount of shared variance between direct and indirect measures as expressed by $\mathrm{R}^{2}$ is relatively limited (around $25 \%$ or less), which means that the direct and indirect measures cannot be equated or seen as tapping into exactly the same construct. In addition, Unsworth (2016) only found correlations between self-ratings and objective measures 
for one of the two languages spoken (English), whereas Lim et al. (2008) did not find correlations between performance measures and self-ratings for one of their subgroups (Mandarin-dominant bilinguals). In addition, it is not clear to what extent the two types of measurements correlate linearly with each other. Relying on indirect measures alone in evaluating language dominance therefore remains problematic, even though the relative simplicity of indirect measures by comparison with direct measures makes them attractive as effective (that is, valid) yet efficient (that is, relatively easily computable) measures of dominance (Unsworth 2016).

A final issue that needs to be investigated in more depth is the relationship between language dominance and the "distributed characteristic" of bilingual knowledge(Oller \& Eilers 2002, p. 10). This means that the knowledge bilinguals have of each of their languages depends on the contexts and purposes for which they use them. Put differently, dominance is domain specific: A bilingual can be dominant in one language in one domain and dominant in another language in another domain. Domain-specific dominance is a direct consequence of the fact that bilinguals use their languages for different purposes, in different domains of life, and with different people (Grosjean 2016); in this regard, Grosjean (1997) coined the notion of the complementarity principle. A key question, then, becomes how such domains are to be defined and operationalized. In a seminal article, Fishman (1965, p. 75) defines a domain of language behavior as a "cluster of social situations typically constrained by a common set of behavior rules." According to Aronin (2013), Fishman developed this notion because he wanted to account for patterns of language use in bilingual contexts, where language choices are linked to specific interlocutors, topics, and situations. Perhaps less known is that, in a footnote, Fishman $\underline{(1965}$, p. 73$)$ already warns that there is no "invariant set of domains applicable to all multilingual settings." Instead, different domains are relevant in different cultures, which considerably complicates studies of language use across domains.

In recent years, several researchers have proposed questionnaires that aim at capturing language use among bilinguals across different domains and interlocutors (Gertken et al. 2014, Marian et al. 2007, Unsworth 2017), sometimes as part of a general questionnaire that focuses on the measurement of language dominance (Dunn \& Fox Tree 2009). Separating language use in broad domains (e.g., home and school) is unlikely to be sufficiently fine-grained to offer new insights into the distributed characteristic of language knowledge. Language use differs not only 
by domain but also by topics or activities, as shown by Jaccard \& Cividin (2001; cited in Grosjean 2016), who asked bilinguals to indicate with which frequency they used each language across 16 different topics. In their study, one bilingual used French $85 \%$ of the time and Italian $15 \%$ of the time to talk about education but used both languages $50 \%$ of the time to talk about leisure. For administration, French was used $40 \%$ of the time; Italian, $60 \%$. This example reveals also that — at least for this bilingual—-language use is not balanced at all if one looks in detail at the domains or functions of language, because the proportions of usage of each language vary considerably per domain or function. In multilinguals, the distribution of labor between the languages is even more complex and even less likely to be balanced, because they use three or four languages on a daily basis for different purposes. Grosjean (2016) elaborates on the complementarity principle by proposing a complementarity index that ranges from $0 \%$, where both languages are used equally for all topics or activities, to 100\%, where all topics or activities are language specific. However, we do not currently have a list of activities or functions that can be used to study language use across different speech communities.

Another way to tap into domain-related differences in language use is to study word associations. Fishman \& Cooper (1969) were among the first to develop a short word association test that asked respondents to name as many words as they could think of in five different domains (family, neighborhood, religion, education, and work). Langdon et al. (2005) also used this Wordlisting by Domain (WLD) test in a study among bilingual Hispanic adults in the United States that aimed at uncovering which tests would be most suitable to measure language dominance, but they found that the test was not very effective in differentiating between dominance groups. This might have been the case because the five domains distinguished in the task were not sufficiently fine-grained to tap into the differences in language use patterns. More insights could be obtained by focusing on specific activities relevant for the speech communities under study, as done by Jaccard \& Cividin (2001).

A final point that needs to be borne in mind is that most studies that analyze exposure to different languages or the use that bilinguals make of different languages are questionnaire based. Of course, such questionnaires provide information only about reported language behavior, and this could be very different from actual language behavior (Labov 1966). Observing actual exposure is possible (see, e.g., Blom 2010) but very time consuming, although such observational data provide more direct information about bilinguals' input and output than 
do questionnaire data.

\section{CONCLUSION}

In this article, I have explored different definitions of language dominance. Whereas most researchers define the concept as the relative proficiency in two languages, an alternative view focuses on differences in the frequency of use of two languages or on the domains for which the different languages are employed. It is clear that proficiency and use - two dimensions that are also key to the bilingual experience itself — are linked, but the strength of the correlations varies from study to study. Operationalizing language dominance in terms of direct measures that tap into aspects of language proficiency is complex because of typological differences between languages and because the level of difficulty of tests in both languages could be different. Indirect measures that assess exposure patterns could be more efficient, but these do not always correlate strongly with direct measures. Therefore, it cannot be taken for granted that indirect measures are valid proxies for direct measures of language dominance.

A limitation of this article is that it has focused mainly on approaches to language dominance in academic contexts. Gertken et al. (2014) point out that dominance is also important in a wide range of domains outside academia, such as public policy, education, commerce, and clinical settings. In educational settings, for example, it is important to set language or math tests in the child's strongest language, and in clinical environments the effectiveness of tests and therapies is affected by the patients' knowledge and frequency of use of both languages (Lim et al. 2008).

Because most research into language dominance has been carried out in European or North American contexts, an important avenue for future research is to obtain evidence from bilinguals from different continents to inform theory building in the field. Research carried out in Asia and Africa is also likely to provide a wealth of information about language dominance in multilinguals, which is welcome because we know very little about the distributed characteristic of language knowledge in this group.

Future research should also focus on analyzing dominance in the different components of language ability distinguished by Bachman \& Palmer (2010). Most studies in the field focus on grammar or vocabulary, but we know virtually nothing about language dominance in bilinguals' sociolinguistic or pragmatic knowledge. Longitudinal studies of the development of language 
dominance over time are also urgently needed, particularly among adults, because most of the literature focuses on language dominance in children. We know very little, for example, about language dominance in adult refugees who have moved to another country with a different societally dominant language. These studies are likely to show that language dominance is even more multifaceted than is currently assumed.

\section{DISCLOSURE STATEMENT}

The author is not aware of any affiliations, memberships, funding, or financial holdings that might be perceived as affecting the objectivity of this review.

I am very grateful to Anne Cutler for inviting me to write this review and for detailed comments made by reviewers on the article. All remaining errors are mine.

\section{LITERATURE CITED}

Altarriba J, Heredia RR. 2011. An Introduction to Bilingualism: Principles and Processes. Oxford, UK: Routledge

Antoniou M. 2019. The advantages of bilingualism debate. Annu. Rev. Linguist. 5. In press. https://doi.org/10.1146/annurev-linguistics-011718-011820

Argyri E, Sorace, A. 2007. Crosslinguistic influence and language dominance in older bilingual children. Biling. Lang. Cogn. 10:79-99

Aronin L. 2013. Fishman, Joshua A. In The Encyclopedia of Applied Linguistics. Oxford, UK: Wiley Online. https://doi.org/10.1002/9781405198431.wbeal0415

Bachman LF, Palmer A. 2010. Language Assessment in Practice. Oxford, UK: Oxford Univ. Press

Bahrick HP, Hall LK, Goggin JP, Bahrick LE, Berger SA. 1994. Fifty years of language maintenance and language dominance in bilingual Hispanic immigrants. J. Exp. Psychol. Gen. 123:264-83

Baker C. 2006. Encyclopedia of Bilingualism and Bilingual Education. Bristol, UK: Multiling. Matters 
Bedore LM, Pena ED, Summers CL, Boerger KM, Resendiz MD, et al. 2012. The measure matters: language dominance profiles across measures in Spanish-English bilingual children. Biling. Lang. Cogn. 15:616-29

Bernardini P, Schlyter S. 2004. Growing syntactic structure and code-mixing in the weaker language: the Ivy Hypothesis. Biling. Lang. Cogn. 7:49-69

Bialystok E, Luk G, Kwan E. 2005. Bilingualism, biliteracy, and learning to read: interactions among languages and writing systems. Sci. Stud. Read. 9:43-61

Bialystok E, Luk G, Peets KF, Yang S. 2010. Receptive vocabulary differences in monolingual and bilingual children. Biling. Lang. Cogn. 13:525-31

Bird H, Franklin S, Howard D. 2001. Age of acquisition and imageability ratings for a large set of words, including verbs and function words. Behav. Res. Methods 33:73-79

Birdsong D. 2016. Dominance in bilingualism: foundations of measurement, with insights from the study of handedness. See Silva-Corvalán \& Treffers-Daller 2016, pp. 85-105

Bishop DVM. 2003. Test for Reception of Grammar 2. London: Pearson

Blom E. 2010. Effects of input on the early grammatical development of bilingual children Int. J. Biling. 14:422-46

Brown R. 1973. A First Language: The Early Stages. Cambridge, MA: Harvard Univ. Press

Chiat S, Armon-Lotem S, Marinis T, Polišenká K, Roy P, Seeff-Gabriel B. 2013. Assessment of language abilities in sequential bilingual children: the potential of sentence imitation tasks. In Issues in the Assessment of Bilinguals, ed. VCM Gathercole, pp. 56-89. Bristol, UK: Multiling. Matters

Cook V. 1991. The poverty-of-the-stimulus argument and multi-competence. Second Lang. Res. $7: 103-17$

Cook V. 2016. Premises of multicompetence. In The Cambridge Handbook of Linguistic MultiCompetence, ed. V Cook, W Li, pp. 1-25. Cambridge, UK: Cambridge Univ. Press

Dale PS, Penfold MM. 2011. Adaptations of the MacArthur-Bates CDI into non-U.S. English languages. MacArthur-Bates CDI, Stanford, CA. http://mb-cdi.stanford.edu/adaptations.html

Daller MH, Yıldız C, de Jong NH, Kan S, Başbağı R. 2011. Language dominance in TurkishGerman bilinguals: methodological aspects of measurements in structurally different languages. Int. J. Biling. 15:215-36

De Houwer A. 1990. The Acquisition of Two Languages from Birth: A Case Study. Cambridge, 
UK: Cambridge Univ. Press

De Houwer A. 1998. By way of introduction: methods in studies of bilingual first language acquisition. Int. J. Biling. 2:249-63

De Houwer A. 2003. Home languages spoken in officially monolingual Flanders: a survey. Plurilingua 24:71-87

De Houwer A. 2007. Parental language input patterns and children's bilingual use. Appl. Psycholinguist. 28:411-24

De Houwer A, Bornstein MH, Putnick, DL. 2014. A bilingual-monolingual comparison of young children's vocabulary size: evidence from comprehension and production. Appl. Psycholinguist. 35:1189-211

De Houwer, A., Bornstein, MH. 2016. Balance patterns in early bilingual acquisition: A longitudinal study of word comprehension and production. See See Silva-Corvalán \& Treffers-Daller 2016, pp. 134-155

Deuchar M, Muntz R. 2003. Factors accounting for code-mixing in an early developing bilingual. In (In)vulnerable Domains in Multilingualism, ed. N Müller, pp. 161-90. Amsterdam: Benjamins

Döpke S. 2000. Generation of and retraction from cross-linguistically motivated structures in bilingual first language acquisition. Biling. Lang. Cogn. 3:209-26

Dunn AL, Fox Tree JE. 2009. A quick, gradient bilingual dominance scale. Biling. Lang. Cogn. 12:273-89

Dunn DM, Dunn LM. 2007. Peabody Picture Vocabulary Test. San Antonio, TX: Pearson Dunn LM, Dunn L, Whetton C, Burley J. 1997. British Picture Vocabulary Scale-II. Windsor, UK: nferNelson

Dunn LM, Lugo D, Padilla E, Dunn L. 1986. Test de Vocabulario en Imagenes Peabody. Circle Pines, MN: Am. Guid. Serv.

Dunn LM, Thériault-Whalen CM, Dunn LM. 1993. Échelle de vocabulaire en images Peabody (EVIP). Pearson. Annu. Rev. Linguist. 2019. 5:X-X https://doi.org/10.1146/annurev-linguistics-011817-045554

Fenson L, Dale PS, Reznick JS, Thal D, Bates E, et al. 1993. The MacArthur Communicative Development Inventories: User's Guide and Technical Manual. San Diego, CA: Singular Firth JR. 1957. A synopsis of linguistic theory, 1930-1955. Reprinted in Palmer, F. R. (ed.) 
(1968). Selected Papers of J. R. Firth 1952-59, pp. 168-205. Longmans, London.

Fishman JA. 1965. Who speaks what language to whom and when? Linguistique 1:67-88

Fishman JA. 1972. Language in Sociocultural Change, vol. 6. Stanford, CA: Stanford Univ. Press

Fishman JA, Cooper RL. 1969. Alternative measures of bilingualism. J. Verbal Learn. Verbal Behav. 8:276-82

Fishman JA, Cooper RL, Ma R. 1968. Alternative measures of bilingualism. In Bilingualism in the Barrio: Final Report, pp. 483-512. ERIC rep. ED026546. Washington, DC: Off. Educ., US Dep. Health Educ. Welf.

Flege JE, MacKay IR, Piske T. 2002. Assessing bilingual dominance. Appl. Psycholinguist. 23:567-98

Gathercole VCM, Thomas, EM. 2007. Prawf geirfa Cymraeg [Welsh vocabulary test]. Sch. Psychol., Bangor Univ., UK. http://www.pgc.bangor.ac.uk

Gathercole VCM, Thomas EM. 2009. Bilingual first-language development: dominant language takeover, threatened minority language take-up. Biling. Lang. Cogn. 12:213-37

Gathercole VCM, Thomas EM, Roberts E, Hughes C, Hughes EK. 2013. Why assessment needs to take exposure into account: vocabulary and grammatical abilities in bilingual children. In Issues in the Assessment of Bilinguals, ed. VCM Gathercole, pp. 20-55. Bristol, UK: Multiling. Matters

Gawlitzek-Maiwald I, Tracy R. 1996. Bilingual bootstrapping. Linguistics 34:901-26

Genesee F, Nicoladis E, Paradis J. 1995. Language differentiation in early bilingual development. J. Child Lang. 22:611-32

Gertken LM, Amengual M, Birdsong D. 2014. Assessing language dominance with the bilingual language profile. In Measuring L2 Proficiency: Perspectives from SLA, ed. P Leclercq, A Edmonds, H Hilton, pp. 208-25. Bristol, UK: Multiling. Matters

Grosjean F. 1985. The bilingual as a competent but specific speaker-hearer. J. Multiling. Multicult. Dev. 6:467-77

Grosjean F. 1989. Neurolinguists, beware! The bilingual is not two monolinguals in one person. Brain Lang. 36:3-15

Grosjean F. 1997. The bilingual individual. Interpreting 2:163-87

Grosjean F. 1998. Studying bilinguals: methodological and conceptual issues. Biling. Lang. 
Cogn. 1:131-49

Grosjean F. 2010. Bilingual: Life and Reality. Cambridge, MA: Harvard Univ. Press

Grosjean F. 2012. An attempt to isolate and then differentiate transfer and interference. Int. J. Biling. 16:11-21

Grosjean F. 2016. The Complementarity Principle and its impact on processing, acquisition, and dominance. See Silva-Corvalán \& Treffers-Daller 2016, pp. 66-84

Gutiérrez-Clellen VF, Restrepo MA, Simón-Cereijido G. 2006. Evaluating the discriminant accuracy of a grammatical measure with Spanish-speaking children. J. Speech Lang. Hear. Res. 49:1209-23

Haitana T, Pitama S, Rucklidge, JJ. 2010. Cultural biases in the Peabody Picture Vocabulary Test-III: testing Tamariki in a New Zealand sample. N. Z. J. Psychol. 39:25-34

Haman E, Łuniewska M, Pomiechowska B. 2015. Designing cross-linguistic lexical tasks (CLTs) for bilingual preschool children. In Methods for Assessing Multilingual Children: Disentangling Bilingualism from Language Impairment, ed. S Armon-Lotem, J de Jong, M Meir, pp. 194-238. Bristol, UK: Multiling. Matters

Hinkel E. 2006. Current perspectives on teaching the four skills. TESOL Q. 40:109-31

Hohenstein J, Eisenberg A, Naigles L. 2006. Is he floating across or crossing afloat? Crossinfluence of L1 and L2 in Spanish-English bilingual adults. Biling. Lang. Cogn. 9:249-61

House J. 1997. Translation Quality Assessment: A Model Revisited. Tübingen, Ger.: Gunter Narr

Hulstijn J. 2012. The construct of language proficiency in the study of bilingualism from a cognitive perspective. Biling. Lang. Cogn. 15:422-33

Jaccard R, Cividin V. 2001. Le principe de complémentarité chez la personne bilingue: Le cas du bilinguisme français-italien en Suisse Romande. Master's thesis, Univ. Neuchâtel, Neuchâtel, Switz.

Jarvis S, Pavlenko A. 2008. Crosslinguistic Influence in Language and Cognition. New York: Routledge

Jia G, Fuse A. 2007. Acquisition of English grammatical morphology by native Mandarin speaking children and adolescents: age-related differences. J. Speech Lang. Hear. Res. 50:1280-99

Jia $G$, Aaronson $D$, Wu $Y$. 2002. Long-term language attainment of bilingual immigrants: Predictive variables and language group differences. Applied Psycholinguistics 23: 599-621 
Kootstra GJ, Doedens WJ. 2016. How multiple sources of experience influence bilingual syntactic choice: immediate and cumulative cross-language effects of structural priming, verb bias, and language dominance. Biling. Lang. Cogn. 19:710-32

Kupisch T. 2008. Dominance, mixing and cross-linguistic influence. In First Language Acquisition of Morphology and Syntax: Perspectives Across Languages and Learners, ed. P Guijarro-Fuentes, P Larrañaga, J Clibbens, pp. 209-34. Amsterdam: Benjamins

Kupisch T, van de Weijer J. 2016. The role of the childhood environment for language dominance: a study of adult simultaneous bilingual speakers of German and French. See Silva-Corvalán \& Treffers-Daller 2016, pp. 174-94

La Morgia F. 2016. Assessing the relationship between input and strength of language development: a study on Italian-English bilingual children. See Silva-Corvalán \& TreffersDaller 2016, pp. 195-218

Labov W. 1966. The Social Stratification of English in New York City. Cambridge, UK: Cambridge Univ. Press

Langdon HW, Wiig EH, Nielsen NP. 2005. Dual-dimension naming speed and languagedominance ratings by bilingual Hispanic adults. Biling. Res. J. 29:319-36

Lanza E. 2004. Language Mixing in Infant Bilingualism: A Sociolinguistic Perspective. Oxford, UK: Oxford Univ. Press

Leopold WF. 1939-1949. Speech Development of a Bilingual Child: A Linguist's Record. Evanston, IL: Northwest. Univ. Press

Lim VP, Liow SJR, Lincoln M, Chan YH, Onslow, M. 2008. Determining language dominance in English-Mandarin bilinguals: development of a self-report classification tool for clinical use. Appl. Psycholinguist. 29:389-412

Luce PA, Pisoni DB. 1998. Recognizing spoken words: the neighborhood activation model. Ear Hear. 19:1-36

Luk G, Bialystok E. 2013. Bilingualism is not a categorical variable: interaction between language proficiency and usage. J. Cogn. Psychol. 25:605-21

Marian V, Blumenfeld HK, Kaushanskaya M. 2007. The Language Experience and Proficiency Questionnaire (LEAP-Q): assessing language profiles in bilinguals and multilinguals. $J$. Speech Lang. Hear. Res. 50:940-67

Marinis T, Armon-Lotem S. 2015. Sentence repetition. In Assessing Multilingual Children: 
Disentangling Bilingualism from Language Impairment, ed. S Armon-Lotem, J de Jong, N Meir, pp. 95-122. Bristol, UK: Multiling. Matters

Meisel JM. 2001. The simultaneous acquisition of two first languages. In Trends in Bilingual Acquisition, ed. J Cenoz, F Genesee, pp. 11-41. Amsterdam: Benjamins

Meisel JM. 2007. The weaker language in early child bilingualism: acquiring a first language as a second language? Appl. Psycholinguist. 28:495-514

Milton J. 2009. Measuring Second Language Vocabulary Acquisition. Bristol, UK: Multiling. Matters

Montrul S. 2016. Dominance and proficiency in early and late bilingualism. See Silva-Corvalán \& Treffers-Daller 2016, pp. 15-35

Nation ISP. 2013. Learning Vocabulary in Another Language. Cambridge, UK: Cambridge Univ. Press. 2nd ed.

Oller K, Eilers RE, eds. 2002. Language and Literacy in Bilingual Children. Bristol, UK: Multiling. Matters

O’Toole C. 2013. Using parent report to assess bilingual vocabulary acquisition: a model from Irish. In Solutions for the Assessment of Bilinguals, ed. VCM Gathercole, pp. 81-102. Bristol, UK: Multiling. Matters

Pavlenko A. 2009. The Bilingual Mental Lexicon: Interdisciplinary Approaches. Bristol, UK: Multiling. Matters

Pavlenko A. 2014. The Bilingual Mind: And What It Tells Us About Language and Thought. Cambridge, UK: Cambridge Univ. Press

Pearson BZ, Fernández SC, Oller DK. 1993. Lexical development in bilingual infants and toddlers: comparison to monolingual norms. Lang. Learn. 43:93-120

Place S, Hoff E. 2011. Properties of dual language exposure that influence two-year-olds' bilingual proficiency. Child Dev. 82:1834-49

Rodd J, Gaskell G, Marslen-Wilson W. 2002. Making sense of semantic ambiguity: semantic competition in lexical access. J. Mem. Lang. 46:245-66

Romaine S. 1989. Bilingualism. Oxford, UK: Blackwell

Scarborough HS, Rescorla L, Tager-Flusberg H, Fowler AE, Sudhalter V. 1991. The relation of utterance length to grammatical complexity in normal and language-disordered groups. Appl. Psycholinguist. 12:23-46 
Schlyter S. 1993. The weaker language in bilingual Swedish-French children. In Progression and Regression in Language: Sociocultural, Neuropsychological, and Linguistic Perspectives, ed. K Hyltenstam, A Viberg, pp. 289-308. Cambridge, UK: Cambridge Univ. Press

Schmeißer A, Hager M, Arnaus Gil L, Jansen V, Geveler J, et al. 2016. Related but different: the two concepts of language dominance and language proficiency. See Silva-Corvalán \& Treffers-Daller 2016, pp. 36-65

Segalowitz N. 2010. Cognitive Bases of Second Language Fluency. London: Routledge

Silva-Corvalán C, Treffers-Daller J, eds. 2016. Language Dominance in Bilinguals: Issues of Measurement and Operationalization. Cambridge, UK: Cambridge Univ. Press

Snape N, Kupisch T. 2016. Second Language Acquisition: Second Language Systems. London: Palgrave Macmillan

Sorace A. 2011. Pinning down the concept of "interface" in bilingualism. Linguist. Approaches Biling. 1:1-33

Sorace A, Serratrice L. 2009. Internal and external interfaces in bilingual language development: beyond structural overlap. Int. J. Biling. 13:195-210

Thordardottir E. 2011. The relationship between bilingual exposure and vocabulary development. Int. J. Biling. 15:426-45

Treffers-Daller J. 2009. Code-switching and transfer: an exploration of similarities and differences. In The Cambridge Handbook of Linguistic Code-Switching, ed. BE Bullock, AJ Toribio, pp. 58-74. Cambridge, UK: Cambridge Univ. Press

Treffers-Daller J. 2016. Language dominance: the construct, its measurement and operationalization. See Silva-Corvalán \& J Treffers-Daller 2016, pp. 235-65

Treffers-Daller J, Korybski T. 2016. Using lexical diversity measures to operationalise language dominance in bilinguals. See Silva-Corvalán \& Treffers-Daller 2016, pp. 106-33

Treffers-Daller J, Parslow P, Williams S. 2018. Back to basics: how measures of lexical diversity can help discriminate between CEFR levels. Appl. Linguist. 39:302-27

Unsworth S. 2016. Amount of exposure as a proxy for dominance in bilingual language acquisition. See Silva-Corvalán \& Treffers-Daller 2016, pp. 156-73

Unsworth S. 2017. BiLEC (Bilingual Language Experience Calculator). Digital parental questionnaire. https://www.iris- 


\section{database.org/iris/app/home/detail?id=york\%3a928327\&ref=search}

Verhoeven L. 2007. Early bilingualism, language transfer, and phonological awareness. Appl. Psycholinguist. 28:425-39

Wang X. 2013. Language dominance in translation priming: evidence from balanced and unbalanced Chinese-English bilinguals. Q. J. Exp. Psychol. 66:727-43

Weinreich U. 1953. Languages in Contact: Findings and Problems. New York: Linguist. Circle N. Y.

Wiig E, Semel E, Secord WA. 2013. Clinical Evaluation of Language Fundamentals. London: Pearson

Wray A. 2000. Formulaic Language and the Lexicon. Cambridge, UK: Cambridge Univ. Press

Yip V, Matthews S. 2006. Assessing language dominance in bilingual acquisition: a case for mean length utterance differentials. Lang. Assess. Q. 3:97-116

Zipf GK. 1945. The meaning-frequency relationship of words. J. Gen. Psychol. 33:251-56

Copyright (C) 2019 by Annual Reviews.

All rights reserved

Treffers-Daller 